\title{
HOMICÍDIOS E CONTROLE SOCIAL FORMAL: UMA ANÁLISE DO PROJETO MUTIRÃO REALIZADO NAS DELEGACIAS DE POLÍCIA EM SÃO LUÍS DO MARANHÃO.
}

\author{
Claudio Alberto Gabriel Guimarães ${ }^{1}$ \\ Márcio Aleandro Correia Teixeira ${ }^{2}$ \\ Marcio dos Santos Rabelo ${ }^{3}$
}

\section{RESUMO}

Análise do controle social formal através do fenômeno jurídico das cifras ocultas da criminalidade extraídas do "Projeto Mutirão de Inquéritos", nos anos de 2017 a 2020, na capital do Estado do Maranhão. Utiliza-se como aporte teórico a Criminologia Crítica para compreensão do funcionamento do controle social. Serão adotados o método de abordagem indutivo e o método de procedimento jurídico-descritivo, valendo-nos da técnica de pesquisa de documentação indireta, abrangendo a pesquisa bibliográfica e a pesquisa documental quantitativa. Conclui-se que as cifras ocultas da criminalidade impactam de forma negativa no controle social formal, o que acaba por refletir ineficiência na persecução penal.

PALAVRAS-CHAVE: Criminologia, Controle social, Cifras Ocultas da Criminalidade, Projeto Mutirão, Polícia Judiciária.

\section{HOMICIDES AND FORMAL SOCIAL CONTROL: AN ANALYSIS OF THE MUTIRÃO PROJECT CARRIED OUT IN POLICE STATIONS IN SÃO LUÍS DO MARANHÃO.}

\begin{abstract}
Analysis of formal social control through the legal phenomenon of hidden crime figures extracted from the "Mutirão de Inquéritos Project", in the years 2017 to 2020, in the capital of the State of Maranhão. Critical Criminology is used as a theoretical support to understand the functioning of social control. The method of inductive approach and the method of legal-descriptive procedure will be adopted, making use of the indirect documentation search technique, encompassing bibliographic research and quantitative documentary research. It is concluded that the hidden numbers of criminality negatively impact formal social control, which ends up reflecting inefficiency in criminal prosecution.
\end{abstract}

KEYWORDS: Criminology, Social Control, Occult Crime Figures, Mutirão Project, Judiciary Police.

\footnotetext{
${ }^{1}$ Professor Permanente da Pós-Graduação em Direito e Instituições do Sistema de Justiça da Universidade Federal do Maranhão e do Programa de Mestrado em Direito e Afirmação de Vulneráveis da Universidade CEUMA. Pós-Doutor pela Universidade de Lisboa. Doutor em Direito pelas Universidades Federal de Santa Catarina e pela Universidade Federal de Pernambuco. Promotor de Justiça. E-mail: calguimaraes@yahoo.com.br

2 Professor Permanente do Programa de Mestrado em Direito e Afirmação de Vulneráveis da Universidade CEUMA. Pós-dourando em Direito e Instituições do Sistema de Justiça da Universidade Federal do Maranhão. Doutor em Políticas Públicas pela Universidade Federal do Maranhão. Advogado. marcio.aleandro@yahoo.com.br.

${ }^{3}$ Mestrando em Direito e Instituições do Sistema de Justiça (UFMA/PPGDIR) adv.marciorabelo@gmail.com
} 


\section{INTRODUÇÃO}

O presente artigo tem como base teórica o controle social formal e como base empírica o "Projeto Mutirão de Inquéritos" realizado nas delegacias de polícia de São Luís, Estado do Maranhão, com o propósito maior de instigar a discussão acerca do funcionamento do sistema de justiça criminal, em uma perspectiva de Teoria Geral do Controle Social, cujos alicerces são edificados, principalmente, no âmbito dos estudos criminológicos.

Sabe-se que violência criminal, atualmente, se coloca como um obstáculo bastante significativo para o alcance das promessas que justificam a existência do Estado, vez que diretamente relacionada a instabilidade de todo o ordenamento jurídico, pelo mau funcionamento das instituições do sistema de controle social formal, impactando no próprio equilíbrio da ordem social.

Nesse passo, foi realizada a análise de fontes documentais referentes ao "Projeto Mutirão de Inquéritos", com vistas à obtenção das informações quantitativas necessárias para a compreensão do desempenho institucional ligado ao controle social formal, coletadas nas delegacias de São Luís e, assim, com base em tais números, utilizar estas informações como suporte para o diagnóstico da referida situação pertinente ao controle institucional.

A hipótese aventada consiste em demonstrar que o controle social formal, encontra-se ineficiente no que se refere à persecução criminal dos crimes de homicídios. Isso pode ser explicado pelo fato da quantidade de inquéritos acumulados nas delegacias da capital. Cabe destacar que o procedimento realizado para a coleta de dados foi especialmente fecundo, buscando-se informações que ultrapassaram as necessidades da presente pesquisa, produzindo, assim, um conjunto de dados válido e rico, que pode subsidiar a análise proposta em um campo com baixa exploração, como é o caso do funcionamento das instituições de controle social formal.

O estudo realizado compreende como problemas centrais os seguintes interrogantes: há incidências relevantes de cifras ocultas da criminalidade nos dados 
obtidos no Projeto Mutirão de Inquéritos? Existem relações entre os inquéritos arquivados de homicídios e a ineficiência do controle social formal?

$\mathrm{Na}$ abordagem adota-se o método indutivo ${ }^{4}$, por se tratar de estudo que opera no campo teórico-interpretativo da realidade. Pretende-se, portanto, a partir das singularidades da pesquisa realizada, alcançar-se aplicação mais geral, pois o caminho metodológico aqui escolhido busca, em última instância, a generalização do conhecimento produzido em um âmbito mais restrito, almejando-se que a hipótese aventada possa servir de parâmetro para outras investigações científicas, a partir de outros recortes temporais e espaciais.

A partir do procedimento descritivo e diagnóstico, a técnica aplicada para a pesquisa é, além da pesquisa bibliográfica, a análise documental ${ }^{5}$ quantitativa dos inquéritos que foram objeto de arquivamento pelo Projeto Mutirão, com base em um recorte espacial, a Comarca de São Luís, assim como, temporal, aqueles arquivados entre os anos de 2017 e 2020.

$\mathrm{Na}$ primeira parte, a pesquisa apresenta o que é o Projeto Mutirão de Inquéritos, desvelando seus objetivos, estrutura, modo de funcionamento, as possibilidades que apresenta como indutor de políticas criminais a serem adotadas no Estado do Maranhão, bem como, chama a atenção para um fato que direciona a presente pesquisa, que é o fenômeno jurídico das cifras ocultas da criminalidade, uma vez que tal fenômeno serve de parâmetro para análise do funcionamento do controle social formal.

No segundo momento, será apresentada a coleta de dados realizada, feita a partir de um recorte limitado aos crimes de homicídio levantados pelo Projeto Mutirão, no transcorrer dos anos de 2017-2020, expondo-se, doravante, as razões e os motivos pelos quais foram objeto de arquivamento proposto pelo Ministério Público.

\footnotetext{
${ }^{4}$ Para melhor esclarecer a aplicação do método indutivo, cita-se o entendimento de Gil (1994, p. 29) no qual o método indutivo "parte do particular e coloca a generalização como um produto posterior do trabalho de coleta de dados particulares".

${ }^{5}$ Para Gil (1994, p. 73) "A pesquisa documental vale-se de materiais que não receberam ainda um tratamento analítico, ou que ainda podem ser reelaborados de acordo com os objetos da pesquisa. $\mathrm{O}$ desenvolvimento da pesquisa documental segue os mesmos passos da pesquisa bibliográfica. Apenas há que se considerar que o primeiro passo consiste na exploração das fontes documentais, que são em grande número. Existem, de um lado, os documentos oficiais, reportagens de jornal, cartas, contratos, diários, filmes, fotografias, gravações etc. de outro lado, existem os documentos de segunda mão, que de alguma forma já foram analisados, tais como: relatórios de pesquisa, relatórios de empresas, tabelas estatística etc.".
} 
No último tópico, descrever-se-á quais os impactos que as ocorrências das cifras ocultas podem trazer ao controle social formal, mormente, se há implicações em seu efetivo funcionamento e as consequências que podem advir de tal fenômeno, limitando-se a uma perspectiva descritiva e diagnóstica do fenômeno investigado.

\section{O QUE É PROJETO MUTIRÃO DE INQUÉRITOS?}

É uma proposta inovadora no Estado do Maranhão, tendo como órgão propositor e organizador o Ministério Público Estadual. O Projeto Mutirão de Inquéritos define as diretrizes para atuação do Ministério Público na efetiva conclusão de inquéritos policiais, cujos delitos ocorreram até o ano de 2015, na cidade de São Luís. Trata-se de uma iniciativa desafiadora, baseada nos princípios que regem o controle social formal, mais precisamente naqueles que informam o devido processo legal ${ }^{6}$.

O Mistério Público do Estado do Maranhão, ao fazer jus à missão institucional na defesa da ordem jurídica, do regime democrático e dos interesses sociais e individuais indisponíveis, não se limitou em observar os inquéritos acumulados nas delegacias de polícia de São Luís, mas de forma planejada, estratégica e conjunta com as forças de segurança pública do Estado, propôs recomendações e providências para sanar as falhas apontadas.

Assim sendo, em setembro de 2016 foi firmado um TAC $^{7}$ (Termo de Ajustamento de Conduta) do Ministério Público com a Cúpula ${ }^{8}$ Estadual de Segurança Pública, com a pretensão de sanar as falhas apontadas, as quais seriam: o baixo efetivo da polícia judiciária, no que se refere ao número reduzido de delegados, peritos, escrivães e investigadores de polícia; alto volume de inquéritos inconclusos nas diversas Unidades de Polícias (delegacias) da capital; ausência de investigação nos crimes graves, prejudicada por forte carga de outras ocorrências de menor gravidade; aumento

\footnotetext{
${ }^{6}$ Para Shecaira (2004), o controle pode ser entendido como certos mecanismos normativos e sanções sociais que são submetidos indivíduos de determinados grupos. Quem sintetiza a ideia de controle social é Hollingshead (1970) ao expressar que do ponto de vista do controle social, a sociedade é um vasto, multiforme e organizado sistema de apelos, sanções, prescrições, usos, e estruturas concentradas para dirigir o comportamento de seus membros dentro de normas culturalmente definidas.

${ }^{7}$ Inquérito Civil no 002/2016 - Portaria Conjunta n ${ }^{\circ} 2106$ que deu origem ao "Projeto Mutirão".

${ }^{8}$ Consiste nos órgãos estaduais de segurança Pública, vinculados ao poder executivo, quais sejam: Secretaria de Estado da Segurança Pública; Delegacia Geral da Polícia Civil; Superintendência de Polícia Civil da Capital e Corregedoria Geral do Sistema Estadual de Segurança Pública.
} 
do número de inquéritos prescritos ou sem qualquer elucidação referente a autoria e materialidade delitiva.

Ademais, o Ministério Público aponta que existem diversas representações formuladas pelo poder judiciário, que descrevem que a única movimentação de inquéritos realizadas em determinados distritos policiais do Estado é o reiterado pedido de dilação do prazo, sem nenhuma diligência cumprida, o que prejudica em muito a efetividade $^{9}$ da persecução criminal.

De início, o Projeto tem como urgência aquelas delegacias da capital, cujo número de Inquéritos inconclusos trazem forte prejuízo para a persecução penal ${ }^{10}$, bem como para todo o sistema de segurança estadual. Em sua práxis, o Projeto Mutirão de inquéritos teve início pela Delegacia de Proteção à Criança e Adolescente no ano de 2016, tendo como objeto de trabalho apenas aquelas delegacias de polícia cujo acúmulo de inquéritos pendentes fosse superior a 150 (cento e cinquenta), bem como a instauração tenha ocorrido antes do ano de 2016. Sendo assim, nesse intervalo ficaram suspensos os procedimentos administrativos relativos a supostos atos de improbidade administrativa cometidos por agentes policiais na tramitação de inquéritos não concluídos até o ano de 2015.

Em síntese, o Projeto Mutirão de Inquéritos teve como desiderato a análise de todos os passivos anteriores ao ano de 2016, cujo inquéritos se encontravam paralisados nas delegacias de São Luís. O procedimento adotado em primeiro momento consistiu na designação de um Delegado de Polícia para tal fim, o qual faria um juízo de admissibilidade do atual andamento do inquérito. Posteriormente, um Promotor de Justiça do controle externo da atividade policial faria uma espécie de segunda análise, optando por três direções: encaminhamento ao promotor natural, em caso de oferecimento de denúncias; pela baixa à delegacia de polícia, para a prática de novas

\footnotetext{
${ }^{9}$ Com o advento da Emenda Constitucional n ${ }^{\circ} 45$, conhecida como reforma do Judiciário, se passou a dispor de maior celeridade no âmbito judicial e administrativo. Nesse sentido, o direito a celeridade, portanto, é substancial tanto à vítima como ao autor do fato. No âmbito penal tenta-se, assim, na linguagem de Távora e Alencar (2017, p. 91) evitar "a procrastinação indeterminada de uma persecução estigmatizadora e cruel."

${ }^{10} \mathrm{Na}$ leitura de Marques (2003, p.138) "a persecutio criminis apresenta dois momentos distintos: o da investigação e da ação penal. Esta consiste no pedido de julgamento da pretensão punitiva, enquanto a primeira é a atividade preparatória da ação penal, de caráter preliminar e informativo: inquisitivo nihil est quam informatio delicti."
} 
diligências; pela promoção de arquivamento, quando ausentes os elementos necessários ao oferecimento da denúncia.

Portanto, o Projeto Mutirão, além de seu caráter inovador, tem contribuído para sanar as falhas da polícia judiciária e, de forma estratégica, planejada, conjunta, entre o Ministério Público estadual e as forças de segurança pública do Estado, possibilita a correção de inúmeros problemas e, até mesmo de irregularidades, que estão a impedir "uma conclusão eficiente de todos os procedimentos policiais da Polícia Judiciária na persecução penal" "11 , bem como evitar que a impunidade não seja a regra, mas a exceção.

Assim sendo, o Projeto Mutirão tem demonstrado ser uma ferramenta indispensável para o aferimento das políticas criminais a serem adotadas no Estado do Maranhão, com vistas ao melhoramento das investigações criminais, assim como, um referencial para que as agências do sistema penal não caiam nas malhas das zonas ocultas da criminalidade, cujo impacto no sistema de controle social formal é o objeto principal desta pesquisa.

Por reconhecerem a profícua contribuição do Projeto Mutirão no âmbito do que acima elencado, o Ministério Público juntamente com os órgãos da Secretaria de Segurança Pública já estabeleceu a prorrogação ${ }^{12}$ do mesmo até ano de 2022, bem como a possibilidade de sua extensão a outras comarcas da Ilha de São Luís.

\section{AS OCORRÊNCIAS DAS CIFRAS OCULTAS NO PROJETO MUTIRÃO}

Etimologicamente, o termo cifra oculta deriva dos termos "dark number" ou "ciffre noir", que pode ser traduzida por zona oculta da criminalidade ou delinquência oculta. Trata-se de um gênero com diferentes espécies ${ }^{13}$, sendo a cifra

\footnotetext{
${ }^{11}$ Palavras utilizados pelo Inquérito Civil no 002/2016 - Portaria Conjunta $n^{\circ} 2106$ que deu origem ao "Projeto Mutirão" (MARANHÃO, 2016).

${ }^{12}$ Em 30 de agosto de 2020, foi feito aditamento do termo de ajustamento prorrogando o Projeto Mutirão de Inquéritos até o mês de julho de 2022, podendo ainda ser prorrogado por mais um ano.

${ }^{13}$ A Doutrina Penal costuma classificar o impacto das cifras ocultas em diversos delitos a partir de subespécies de cifras, que foram classificadas por cores. As cifras douradas consistem na criminalidade do colarinho branco. São aquelas práticas sociais que ficam impunes realizadas por pessoas de forte poder político e econômico. Enfim essas pessoas são imunizadas pelas suas condições sociais. As cifras cinzas são resultados de delitos que, apesar de serem registrados, as vítimas não dão continuidade ao andamento do caso. Também é aquela que ocorre por inoperância do Estado quando não dá andamento no caso e este acaba caindo no esquecimento. As cifras amarelas consistem naquelas onde as vítimas são pessoas que sofrem alguma forma de violência por um agente estatal. Em regra, o crime é praticado pelo Estado
} 
oculta a genitora de todas as demais. As cifras ocultas da criminalidade se apresentam como um fenômeno estudado pela criminologia no qual vários crimes acabam por convergir para as estatísticas da impunidade. Esse fenômeno foi paulatinamente evoluindo como tentativa de mostrar dados informativos da realidade criminal. Desse modo, na realidade social existe muitos delitos e delinquentes que, para Hassemer e Muñoz Conde (2008), não chegam a ser descobertos ou mesmo procedimentalizados pelo sistema penal.

Ao extrair as informações atinentes aos inquéritos arquivados dos crimes de homicídios do Projeto Mutirão, constata-se que tais informações podem ser discutidas de diferentes maneiras. São informações importantes, pois o que predomina no sistema de justiça criminal é a ausência de dados ${ }^{14}$ confiáveis para determinar a incidência de cifras ocultas da criminalidade.

Nessa senda, a partir dos dados coletados, a presente exposição analisa o funcionamento do controle institucional da criminalidade, tendo como aporte teórico a criminologia crítica ${ }^{15}$, ao discutir as possíveis incidências das cifras ocultas ${ }^{16}$ da criminalidade e seus impactos no real funcionamento do controle social formal.

contra a sociedade. As cifras verdes, por sua vez, configuram naquelas que não chegam ao conhecimento do Estado, pois não possuem voz ativa, ou porque a autoria é difícil de ser constatada. Nesse sentido, os crimes ambientais que desenvolvem ínfimas reações sociais aparecem como exemplo dessa modalidade de cifra. Por fim, as cifras rosas se referem a grupos vulneráveis, em especial aqueles que tendem a sofrer maiores violências, essencialmente físicas, como as violências contra as mulheres e população LGBTQIA+ (Lésbicas, Gays, Bissexuais, Transsexuais, Queer, Intersexo, Assexual, etc). (BIFFE JÚNIOR e LEITÃO JÚNIOR, 2017, p. 38)

${ }^{14}$ No entendimento de Lemgruber (2002, p. 157) não existem dados confiáveis para determinar a cifra oculta ou taxa oculta, isto é, a diferença entre o número de crimes cometidos e aqueles que chegam ao conhecimento da polícia. Tampouco se pode conhecer a "taxa de atrito", ou proporção das perdas que ocorrem em cada instancia do sistema de justiça criminal, a partir doo número de crimes cometidos, culminando com o número de infratores que recebem uma pena de prisão. Outra incógnita é a taxa de esclarecimento de crimes - quantidade de crimes em relação aos quais a polícia é capaz de indicar ao Judiciário um provável culpado, tomando-se como ponto de partida o número de crimes registrados. Em suam, não contamos com indicadores fundamentais de funcionamento e eficácia do sistema, sendo impossível avaliá-la objetivamente.

${ }^{15}$ Para Baratta (2019, p. 208) a criminologia crítica foi concebida, desde seu início como uma construção processual. Tanto assim que passou a ocupar nos últimos tempos, um lugar fundamental na análise dos sistemas penais vigentes, bem como ocupar um lugar cada vez mais central no interior do objeto da investigação criminológica.

${ }^{16} \mathrm{Na}$ perspectiva de Cervini (1995, p. 164) há vários decênios, a atenção de muitos criminólogos e sociólogos têm sido atraída por esse fenômeno chamado de "cifra oculta" ou "campo obscuro da delinquência" ainda que a partir de um enfoque que, como diz Hulsman, não era especificamente de crítica ao sistema. 
Assim, para melhor esclarecimento, verifica-se a eficácia do sistema de controle social formal na ilha de São Luís sob a perspectiva, mais próxima, do controle realizado pela Polícia Judiciária e Ministério Público.

Para tal análise, entretanto, buscaram-se informações mais amplas, que extrapolam a esfera das cifras ocultas, elaborando-se as seguintes indagações: quantos inquéritos referentes à homicídios foram arquivados? Por que foram arquivados? Quais os tipos de homicídios encontrados? Como é a distribuição em relação ao gênero, no que diz respeito a autoria e vítima? Em qual ano ocorreu o maior número de arquivamento de crimes de homicídios? Qual a distribuição espacial do crime de homicídio no contexto da ilha de São Luís? Quais as razões de arquivamentos encontradas com maior frequência?

Na pesquisa ficou demonstrado que 552 inquéritos já foram encaminhados ao arquivamento pelo Projeto Mutirão entre os anos de 2017 a 2020. Entre os principais crimes apresentados estão: estupro de vulnerável, roubo, furto, latrocínio e homicídios. Desse total, constatou-se que 102 inquéritos arquivados tinham por natureza o crime de homicídio. Obteve-se assim, um recorte para análise das ocorrências das cifras ocultas, cuja natureza criminal tratava-se de homicídios tentados e consumados.

Dos dados coletados, aponta-se um total de $79(77,5 \%)$ de homicídio simples nos inquéritos instaurados. Um total de 11 (10,8\%) de homicídios qualificados e um total de $11(10,8 \%)$ de homicídios tentados. Apenas uma (0,98 \%) ocorrência de homicídio culposo. Chama a atenção o fato de que grande parte desses homicídios serem perpetrados por armas de fogo e por autores que nunca foram identificados.

No que tange ao número de arquivamentos durante os anos de 2017 a 2020 dos crimes de homicídios, a menor incidência de pedidos deu-se no ano de 2017 com 6 $(5,9 \%)$ pedidos de arquivamentos. Em 2018, totalizaram-se $18(17,6 \%)$ pedidos de arquivamento. $\mathrm{O}$ ano de 2019 teve sua maior incidência com 57 (55,9\%) pedidos de arquivamentos, diminuindo para apenas $21(20,6 \%)$ no ano subsequente. Observa-se que essa diminuição no número de inquéritos arquivados em 2020 pode ser explicada pela grave crise epidemiológica advinda da pandemia do novo coronavírus, o que provocou a suspensão de atividades presenciais. 
Merece destaque, sendo uma outra variável importante, a data do fato dos crimes então analisados. Ressalte-se que o Mutirão de Inquéritos teve como finalidade analisar apenas aquelas ocorrências anteriores ao ano de 2016.

Nesse sentido, ao analisar os inquéritos de homicídios inconclusos, observou-se que o crime com data mais antiga ocorreu no ano de 1999, com apenas uma ocorrência (0,98\%). Os anos 2000, 2002, 2003, 2004 e 2009 também contaram com uma única ocorrência cada, totalizando (4,9\%). Os anos 2005 e 2006, duas ocorrências cada, totalizando (3,92\%). O ano de 2007 apresentou 7 (6,86\%) ocorrências. Em 2010 foram 5 (4,9\%) ocorrências. No ano de 2011 foram 4 (3,92\%) ocorrências, sendo que em 2012 e 2013 foram 11(10,78\%) ocorrências em cada ano. Observou-se o maior número de ocorrências no ano de 2015, com 27 (26,47\%) ocorrências, e em seguida o ano de 2014, com $17(16,67 \%)$ ocorrências. Apesar do mutirão analisar os crimes anteriores a 2016, os crimes ocorridos em 2014 e 2015 tiveram números consideravelmente maiores de análise frente ao arquivamento. Chama atenção o ano de 2008, que diferente dos anos anteriores e dos três anos subsequentes, obteve 10 (9,80\%) ocorrências.

Para uma melhor compreensão do contexto analisado, faz-se necessário enumerar outras variáveis encontradas na pesquisa que evidenciam uma realidade apresentada pelos crimes violentos, na qual figuram como vítimas mais homens que mulheres. Da amostragem de 102 inquéritos arquivados, a partir de leitura do contexto do gênero das vítimas, identificou-se que apenas $5(4,9 \%)$ eram do gênero feminino, sendo $97(95,1 \%)$ do gênero masculino vítimas dos homicídios pesquisados.

No que pertine a autoria dos inqueridos analisados, o presente estudo apontou que $2(1,9 \%)$ inquéritos tinham por sujeito ativo pessoas do gênero feminino e $38(37,3 \%)$ eram do gênero masculino. A pesquisa indica um total de $62(60,8 \%)$ inquéritos em que o autor do fato é desconhecido. Essa variável demonstra que mais de $60 \%$ dos homicídios arquivados não tiveram a autoria elucidada, refletindo, assim, os problemas relacionados com o exercício da investigação levada a cabo pela Polícia Civil.

No que diz respeito a análise das razões do arquivamento, um total de 69 $(67,7 \%)$ inquéritos foram arquivados por ausência de autoria delitiva, o que inviabiliza a 
justa causa para o oferecimento da ação penal. Um total de $16(15,7 \%)$ inquéritos foram arquivados em razão da extinção de punibilidade pela morte do autor, caracterizando a extinção da punibilidade. Um total de $12(11,8 \%)$ inquéritos além da não identificação da autoria não apresentavam, também, os elementos mínimos de materialidade, o que impossibilitou o oferecimento da denúncia.

Ademias, um total de $2(1,2 \%)$ inquéritos foram arquivados em razão do princípio non bis idem, ou seja, a existência de outros inquéritos da mesma natureza com as mesmas circunstâncias fáticas em andamento impossibilitou o oferecimento da denúncia. Um $1(0,9 \%)$ inquérito foi arquivado pelo acolhimento de excludente de ilicitude, um $1(0,9 \%)$ inquérito arquivado pela impossibilidade de localização do autor, sendo esgotadas todas as tentativas realizadas e, por fim, um $1(0,9 \%)$ inquérito foi arquivado pela extinção da punibilidade em razão da prescrição.

Quanto a distribuição espacial dos crimes de homicídios analisados, 31 $(30,4 \%)$. não tiveram a localidade informada. As demais ocorrências dos homicídios foram registras em bairros periféricos - de população menos favorecida economicamente - da Grande São Luís, quais sejam: um total de 15 (14,7\%) na Cidade Olímpica, 14 (13,7\%) no bairro Coroadinho, 7 (6,9\%) no Maiobão (Paço do Lumiar), 5 (4,9\%) na Vila Embratel, 4 (3,9\%) na Santa Clara e 3 (2,9\%) no Sá Viana. Nos bairros Cidade Operária, Vila Conceição, Vila Isabel Cafeteira, Vila Vitória e Paranã (Paço do Lumiar) tiveram 2 (1,9\%) ocorrências cada. Já os bairros de Araçagy, Areinha, Centro, Cohab, Cohatrac, Jaguarema, Planalto Turu, Primavera Bom Jesus, Residencial Alexandra Tavares, Santana (São Jose de Ribamar), São Cristovão, Sol e Mar, Vila do Povo (Paço do Lumiar) tiveram uma $1(0,9 \%)$ ocorrência cada ${ }^{17}$.

De todo o exposto, percebe-se, que o estudo sobre o Mutirão de Inquéritos apresenta estatísticas que são úteis para um aprofundamento da análise acerca do funcionamento do controle social formal, haja vista que evidencia a ocorrência de cifras

${ }^{17} \mathrm{O}$ fenômeno da espacialização dos crimes, foi bem estudado pelos sociólogos da Escola de Chicago que, já no alvorecer do século XX, entenderam que o fenômeno da criminalidade, está umbilicalmente ligado a ideia de desorganização social e urbana. Nesse sentido, se não houver controle social informal, necessariamente haverá desorganização social, amiúde, muito próxima da desorganização urbana. Nessa perspectiva sociológica, o controle social seria um esforço coletivo no sentido de impor aos indivíduos um conjunto de valores entendidos como definidores de um determinado grupo social. No entendimento de Pablos de Molina e Gomes (2002, p. 67) essa teoria “explica o efeito criminógeno das grandes cidades, valendo-se dos conceitos de desorganização e contágio inerente aos modernos núcleos urbanos e, sobretudo, invocando o debilitamento do controle social desses núcleos". 
ocultas da criminalidade, que acabam por refletir falhas das agências de controle social formal. Os dados obtidos, portanto, trazem indicativos para análise de crimes violentos, assim como, um diagnóstico do funcionamento do social formal na grande ilha de São Luís, lançando luzes sobre possíveis políticas públicas a serem adotadas para melhoramento ao exercício desse controle institucional.

\section{O IMPACTO DA CIFRA OCULTA NO FUNCIONAMENTO DO CONTROLE SOCIAL FORMAL}

Antes de apresentar os impactos das cifras da criminalidade oculta no funcionamento do controle social, faz-se necessário um breve resgate da origem da ideia de controle no pensamento moderno e sua relação com o sistema penal. Assim, em sua forma histórica, o controle social ${ }^{18}$ está atrelado a ideia de Estado. Dessa forma, lá onde estiver o Estado, lá estará o controle social.

Entretanto, necessário pontuar, a ideia de controle social não é exatamente moderna, haja vista que em qualquer sociedade, por mais arcaica que fosse, a disciplina sempre fez parte dela. Portanto, nunca houve sociedade sem disciplina. Nesse sentido, o controle social é considerado um tema clássico que desperta a atenção dos pensadores desde a Grécia Antiga ${ }^{19}$ até os dias atuais.

Assim sendo, o controle e a disciplina acabaram por propiciar com que o Estado prosperasse mesmo que em diferentes perfis. Mas é sobretudo com a modernidade que a ideia de disciplina alcançará seu apogeu, haja vista que nas mais diferentes formas de Estado que se desenvolveram em tal período histórico - capitalista,

\footnotetext{
${ }^{18}$ Para Marcantonio (2013, p. 189) o controle social a partir da modernidade pode ser entendido assim: "O controle produzido pela institucionalização de uma determinada sociedade se faz mediante o que podemos denominar controle social. Como dito, essa espécie de controle está arraigada no comportamento individual, mediante uma espécie de coercibilidade coletiva. Assim, a atuação da instituição se articula pretensamente como objetivo dentro da perspectiva social, mas a dinâmica de seus institutos se dá ainda a partir da perspectiva do sujeito. O que faz, em última análise, uma instituição é estabelecer um controle social mediante sua capacidade de justificação de mundo, a partir da leitura das relações e dinâmicas sociais, construindo, paulatinamente, a percepção e o sentido do mundo e das coisas que lhe pertencem. Assim, a modernidade se utiliza das instituições sociais como forma de reificação, ou seja, como sendo a autoridade para interpretar as formas de se relacionar com o mundo e o que tais formas significam. Assim, o universo do controle e do poder simbólico nunca esteve afastado do processo de construção da realidade moderna".

${ }^{19}$ O livro a República de Platão, escrito no século IV a.C., obra considerada como o primeiro tratado de filosofia política, o controle social aparece atrelado a ideia de justiça. Para Platão (2000) a cidade justa é aquela governada pelos filósofos; tal cidade é composta por cidadãos justos. Portanto cidadão justo é o homem justo, sujeito e objeto do controle social.
} 
socialista, fascista, nazista, totalitários, democráticos etc. -, a disciplina sempre se fez presente como pedra angular e, consequentemente, como âncora de legitimação do status quo ${ }^{20}$. (FOUCAULT, 2009)

Nessa perspectiva, afirma-se que o Estado é um fenômeno original, dinâmico e histórico de dominação; em cada momento histórico e correspondente modo de produção prevalece um determinado tipo de Estado. Assim, o Estado em sua versão de natureza absolutista, se constituiu como forma de transição do período medieval, como um sistema da sociedade estamental ${ }^{21}$, para o Estado moderno, no qual emergiu a ideia de contratualismo, uma forma de pensamento que floresceu no intercurso dos séculos XVI a XVIII. Sua estrutura básica se deu pela contraposição entre o estado de natureza e o estado civil mediado pelo contrato social. Dessa forma, o contrato social aparece como instrumento de legitimação do Estado, para uma base de construção do sistema jurídico.

A partir do século XVIII emerge a passagem do Estado moderno para o contemporâneo. Essa passagem é marcada não por um evento isolado, mas decorre de um processo dinâmico, na qual a estrutura político jurídica é marcada pela ideia de direito e democracia.

Em tal contexto, paulatinamente, concretiza-se o modelo de Estado Constitucional e Democrático de Direito, no qual faz-se, cada vez mais claramente, a distinção entre as formas de controle que devem ser exercidos como forma de manutenção e proteção da ordem social e da ordem jurídica.

Nesse sentido, na contemporaneidade, para Baratta (2019) a sociologia jurídica, ao tomar como objeto de estudo as relações entre o direito e outros setores da ordem social, acaba por levar em consideração, como fator preponderante, a reação

\footnotetext{
${ }^{20}$ Nesse sentido, no entendimento de Foucault (2009, p. 239) "pode-se então falar, em suma, da formação de uma sociedade disciplinar nesse movimento que vai das disciplinas fechadas, espécie de "quarentena" social, até o mecanismo indefinidamente generalizável do "panoptismo". Não que a modalidade disciplinar do poder tenha substituído todas as outras; mas porque ela se infiltrou no meio das outras, desqualificando-as às vezes, mas servindo-lhes de intermediária, ligando-as entre si, prolongando-as, e principalmente permitindo conduzir os efeitos de poder até os elementos mais tênues e mais longínquos. Ela assegura uma distribuição infinitesimal das relações de poder."

${ }^{21}$ Para Brandão (2020, p. 92) a concepção individualista do Estado e do Direito representou a quebra com o sistema da sociedade estamental e com a concepção naturalista, pelo menos com o naturalismo teológico, e criou as condições e possibilidades para a declaração de direitos de garantias, liberdade, propriedade e segurança para os cidadãos.
} 
social ao comportamento do desviante como referência para análise deste objeto. Assim, a ideia de controle social nessa vertente criminológica - Criminologia Crítica -, pode ser dividida em controle social não institucional (controle social informal) e em controle social do desvio (controle social formal), que é exercido por meio do direito e dos órgãos oficiais de sua aplicação no âmbito criminal.

Nessa perspectiva, para Guimarães (2018) o controle social se divide em controle social informal $^{22}$ e controle social formal. O primeiro é representado pela família, escola, comunidade, religião, dentre outras instituições não estatais. O segundo é exercido de forma direta pelo Estado, que impõe aos indivíduos que vão de encontro aos seus comandos, as sanções com suas respectivas funções.

Especificamente em relação ao nosso objeto de estudo, dentre todas as formas de controle social, aquele afeto ao Estado, imanente às suas atribuições, é o exercido pelo sistema criminal. Para Zaffaroni e Pierangeli (2007), o sistema penal é um controle punitivo institucionalizado, que visa a imposição de uma punição à uma pessoa que infringe as regras de uma determinada sociedade. No mesmo entendimento, Batista (1990) afirma que a função do direito de estruturar e garantir determinada ordem econômica e social, à qual estamos nos referindo, é habitualmente chamada de "função conservadora" ou de "controle social",23.

\footnotetext{
${ }^{22}$ No entendimento de Valladares (2018, p. 58) ao estudar a sociologia urbana de Robert E. Park, existe uma crise pela qual passa controle social informal no ambiente urbano, advertindo que "em uma grande cidade, onde a população é instável, onde pais e filhos trabalham fora e, muitas vezes, em partes distintas da cidade, onde milhares de pessoas vivem anos lado a lado sem sequer se cumprimentarem, as relações de proximidade do grupos primário foram enfraquecidas e a ordem moral que se baseava nelas foi gradualmente dissolvida. Sob as influências desagregadoras da vida na cidade, a maior parte de nossas instituições - a igreja, a escola e a família - sofreram muitas modificações. A escola, por exemplo, assumiu algumas funções da família "[...] por outro lado, a igreja perdeu muito de sua influência desde que a página impressa ocupou em grande medida o lugar do púlpito na interpretação da vida, parece atualmente em processo de readaptação as novas condições."

${ }^{23}$ Para uma melhor compreensão da matéria, cfr., Zaffaroni (1991, p. 65-66) que entende o sistema penal como aquele que engloba a atividade do legislador, do público, da polícia, dos juízes e funcionários da execução penal, ou seja, nas palavras do autor: "Chamamos 'sistema penal' ao controle social punitivo institucionalizado, que na prática abarca desde que se detecta ou supõe detectar-se uma suspeita de delito até que se impõe e executa uma pena, pressupondo uma atividade normativa que cria a lei que institucionaliza o procedimento, a atuação penal. Assim, o sistema penal e sua instancias e instiuições agem para assegurar a paz social, bem como garantir a defesa social desde que como se pode ver, a pena privativa de liberdade é o centro de gravidade da nova política penal brasileira, como ponto de convergência repressiva e núcleo de irradiação da eficácia coativa das penas restritivas de direitos." No mesmo sentido, cfr., (SANTOS, 2005).
} 
Do exposto, fica evidentemente, que o Estado é por excelência o responsável, de forma exclusiva, pela resolução dos conflitos entre particulares por meio da ordem jurídica. Assim, quando os conflitos envolvem bens juridicamente elevados à categoria de bens jurídicos penais, o Estado tem o monopólio do ius puniendi, uma espécie de violência institucional, necessária para a utilização exclusiva do controle social formal.

E é exatamente na esfera de tal controle que está inserta a pesquisa realizada no presente trabalho. Intentou-se, pois, investigar qual o impacto das cifras ocultas da criminalidade no controle social formal.

Nesse desiderato, ficou demonstrado que o sistema penal pesquisado espacial e temporalmete recortado -, opera envolto no fenômeno geral da cifra oculta, sem que se possa precisar em que nível percentual, haja vista náo se ter acesso a números totais de Inquéritos instaurados nos anos pesquisados, em razão de não estar tal universo dentro da operacionalidade do Mutirão de Inquéritos.

Entretanto, a pesquisa da cifra oculta em crime grave (homicídio), dentro do universo da cifra oculta geral, demostra números significativos, vez que 102 Inquéritos Policiais foram arquivados nas investigações por crimes de homicídio, em um universo de 552 Inquéritos Policiais que arquivaram delitos de diversas naturezas.

Logo, um percentual acima de $18 \%$ de cifra oculta da criminalidade, exclusivamente em crimes de homicídio, o mais grave de todo o ordenamento jurídico penal - protege o bem mais valioso do ser humano, a vida -, acaba por demonstrar uma preocupante ineficiência do controle social formal, vez que até mesmo os crimes de máxima gravidade, conforme demonstrado, acabam por constituir índices significativos de cifras da criminalidade oculta ${ }^{24}$.

Ademais, os dados levantados apontam a existência de inquéritos policiais sem quaisquer movimentações por mais de uma década, desde o ano de 1999 até o ano

\footnotetext{
${ }^{24}$ Na perspectiva de Guimarães (2010, p. 67) os autos índices de cifra oculta da criminalidade, por si sós deixam a descoberto a ineficácia do sistema penal, o que levaria a crer que as leis penais são promulgadas com um único fim de atender as exigências da opinião pública em relação à segurança, criando na população a ilusão de que providencias estão sendo tomadas apesar da total impossibilidade de sua concretização.
} 
de 2015 a totalidade das investigações se quedou inerte, prejudicando qualquer possibilidade de desenvolvimento da persecução penal, propiciando, assim, a impunidade. Não existem justificativas a abalizarem que um delito, em especial um homicídio, permaneça conhecido pelos órgãos de controle e não haja nenhuma iniciativa na tentativa de elucidação destes.

Nesse sentido, para Hassemer (2008) e Muñoz Conde, a falta de esclarecimento nas investigações gera prejuízo doloroso na elucidação dos crimes, o que acaba por arrastar o crime ao rol das cifras ocultas. Isso ocorre por exemplo desde uma perícia mal-sucedida até a deficiência pela autoridade policial no levantamento das provas. Tal análise também é corroborada por Andrade (1997), ao retratar que muitos crimes não chegam a trilhar o caminho normal da investigação, e acabam por serem arrastados às cifras ocultas.

Tudo o que exposto como fruto da pesquisa retratada no presente texto acarreta uma principal e perversa conclusão: o absoluto enfraquecimento do sistema de controle social formal, que não está a alcançar os objetivos históricos a ele atribuídos.

Em síntese e finalmente, necessário se faz analisar os impactos que a cifra oculta da criminalidade, refletida na impunidade que acarreta entrave no sistema de justiça criminal.

Assim, um olhar que merece destaque é sobre a impunidade. As cifras ocultas da criminalidade identificadas neste trabalho acabam por elucidar que a impunidade gerada pelas deficiências na investigação é bastante considerável, o que reforça a percepção da ineficiência do controle social formal.

Dessarte, toda a complexa construção teórica do Estado Moderno, e a necessária confiança da população como elemento vital à legitimidade do sistema jurídico político vigente, fica bastante prejudicada em meio a falta de esclarecimentos de investigação de crimes de natureza grave, a exemplo dos homicídios cujos inquéritos foram arquivados.

Nunca é demais lembrar dos fundamentos que se constituíram como a base teórica para a edificação do atual modelo de Estado que está a gerir a ordem social pela via da ordem jurídica na atualidade: a solução institucionalizada de conflitos 
intersubjetivos como forma de se evitar a realização da justiça com as próprias mãos ou a prevalência da lei do mais forte.

\section{CONSIDERAÇÕES FINAIS}

Parte-se da premissa que toda conclusão não deixa de ser um ponto de vista sobre determinada realidade estudada, comprovada, defendida, mesmo que temporariamente, uma vez que no campo da ciência não há dogmas, pois tudo é refutável.

Assim, a presente investigação partiu da realidade apresentada pelo Projeto Mutirão de inquéritos até chegar ao fenômeno jurídico das cifras ocultas da criminalidade. Dessa forma, os dados extraídos desta pesquisa documental, por meio do Projeto Mutirão, incidem na ocorrência de cifras ocultas, no âmbito dos crimes de homicidios na ilha de São Luis.

Rememorando o que foi outrora exposto, oberva-se tão importante foi o Projeto Mutirão, como âncora capaz de desnudar a realidade presente, pois através desse mecanismo chegau-se a descobertas de dados que possibilitaram a presente pesquisa. Nessa sentido, o Minitério Público do Maranhão cumpre sua função institucional ao sair do status quo, considerando a realidade das delegacias da capital do Estado e propondo soluções como aquelas já sustentadas acima.

Além disso, os dados falam por sí: primeiramente, a partir do embasamento proporcionado pela criminologia crítica, é possivel apontar as falhas pela qual passa o funcionamento desse controle social formal, assim, pode-se fazer algumas constatações que serão abaixo descritas.

A primeira deles concerne ao resgate de crimes de homicídios que "cairam no esquecimento" (1999-2015) pelo mau funcionamente desse controle social formal. Aponta-se que as incidências de arquivamento com maior destaque ocorreram nos anos de $2014(16,67 \%)$ e $2015(26,47 \%)$. Que o percentual de vítimas mulheres $(4,9 \%)$ é menor nos crimes de homícidios que o homens $(95,1 \%)$. Que o total de inquéritos em que o autor do fato é desconhecido chega a $(60,8 \%)$ das ocorrências. Que $(67,7 \%)$ dos inquéritos foram arquivados por ausência de autoria delitiva. Que $(30,4 \%)$ dos crimes analisados não tiveram a localidade informada. 
Ademais disso, no campo investigativo de analíse das cifras ocultas da criminalidade, por meio do Projeto Mutirão, constata-se a real impunidade que fere um dos bens jurídicos mais ricos: a vida humana. Nesse sentido, a pesquisa traz forte aferição do mau funcionamento do sistema penal. Conforme observado pela pesquisa documental realizada, os bens jurídicos penais, diga-se de passagem, aqueles bens jurídicos mais caros ao corpo social, não são devidamente protegidos em sua essência. Isso acaba por legitimar uma realidade irracional como a aferimento de cifras ocultas.

Desta feita, diante dos dados apresentados é que se constata que o fenômeno das cifras ocultas trazem impactos negativos no funcionamento do controle social formal, em especial à investigação criminal, em que crimes de natureza gravíssima, a exemplo de homicidios, não chegam ao devido esclarecimento pelo orgãos de controle social formal. Assim, observa-se que os números levantados apontam na direção de uma situação problemática pelas quais passam os orgãos de segurança pública do Estado, de forma mais específica as delegacias de São Luís.

Observa-se, ainda, a importância do Projeto Mutirão, que se apresenta como uma alternativa para a aproximação e fortalecimento das instituições de controle, que apesar do seu caráter provisório, aponta as deficiências a serem sanadas pela polícia judiciária, a fim de evitar a ocorrência das cifras ocultas da criminalidade, principalmente em crimes graves como os homicídios.

Por fim, é indispensavel pontuar que a presente estudo pode proporcionar um subsídio importante para o monitoramento e avaliação das políticas públicas de segurança no Estado do Maranhão. Assim, entende-se que esta pesquisa, com base de análise na Criminologia Crítica, ressalta a importância do fenômeno da cifras ocultas da criminalidade como meio indispensável para entender o real funcimamento do controle social formal no âmbito de um Estado de Direito.

\section{REFERÊNCIAS}

ANDRADE, Vera Regina Pereira de. A ilusão de segurança jurídica: do controle da violência à violência do controle penal. Porto Alegre : Livraria do Advogado, 1997 
ANDRADE, Vera Regina Pereira de. Pelas mãos da criminologia: o controle penal para além (des)ilusão. Rio de Janeiro: Renan, 2012.

BARATTA, Alessandro. Criminologia Crítica e Crítica do Direito Penal: introdução à sociologia do direito penal. Tradução Juarez Cirino dos Santos. $6^{\mathrm{a}}$ ed. Rio de Janeiro: Revan, 2019.

BATISTA, Nilo. Introdução crítica ao direito penal brasileiro. Rio de Janeiro : Revan, 1990.

BIFFE JUNIOR, João; LEITÃO JUNIOR, Joaquim. Concursos Públicos Terminologias e Teorias Inusitadas. Rio de Janeiro: Forense; São Paulo: Método, 2017.

BRANDÃO, Paulo de Tarso. Normas de Direitos Fundamentais: um estudo sobre o nível das regras. Florianópolis: Habitus, 2020.

CERVINI, Raúl. Os processos de descriminalização. Trad. Eliana Granja. São Paulo: Revista dos Tribunais, 1995.

FOUCAULT, Michel. Vigiar e punir: nascimento da prisão. 36a . ed. Tradução de Raquel Ramalhete. Petrópolis, RJ: Vozes, 2009.

GIL, Antônio Carlos. Métodos e técnicas de pesquisa social. São Paulo: Atlas, 1994.

GUIMAR ÃES, Claudio Alberto Gabriel. Ministério Público e Direito Penal. A defesa do Estado Democrático no âmbito punitivo. Rio de Janeiro: Revan, 2010.

GUIMARÃES, Claudio Alberto Gabriel. Teorias críticas e direito criminal: sobre os fundamentos e a legitimação do direito de punir. Rio de Janeiro: Revan, 2018.

HASSEMER, Winfried; MUÑOZ CONDE, Francisco. Introdução à Criminologia. Trad. Cíntia Toledo Miranda Chaves. Rio de Janeiro: Lúmen Juris, 2008.

HOLLINGSHEAD, A.B. Controle Social. In: PIERSON, Donald. Estudos de Organização Social. São Paulo: Martins, 1970.

LEMGRUBER, Julita. Insegurança Pública: Reflexões sobre a criminalidade e a violência Urbana. Org. Nilson Vieira Oliveira. São Paulo: Nova Alexandria, 2002.

MARANHÃO. Ministério Público Estadual. Promotoria de Justiça do Controle Externo da Atividade Policial. Inquérito Civil no 002/2016 - Portaria Conjunta no 2106. São Luís, 2016.

MARCANTONIO, Jonathan Hernandes. Direito e Controle Social na modernidade. São Paulo: Saraiva, 2013.

PABLOS DE MOLINA, Antonio Garcia; GOMES, Luiz Flávio. Criminologia: Introdução a seus fundamentos teóricos. São Paulo: RT, 2002.

OLIVEIRA, Olga Maria Boschi Aguiar de. Monografia jurídica: orientações metodológicas para o Trabalho de Conclusão de Curso. 3. ed. Florianópolis: Síntese, 2003.

PLATÃO. A República. 3. ed. Belém: EDUFPA, 2000. 
SANTOS, Juarez Cirino dos. Teoria da Pena. Curitiba ICPC: Lúmen Juris, 2005.

SHECAIRA, Sergio Salomão. Criminologia. São Paulo: RT, 2004.

TÁVORA, Nestor; ALENCAR, Rosmar Rodrigues. Curso de direito processual penal. 12 ed. Salvador: Juspodivm, 2017.

VAlladARES, Licia do Prado. A Sociologia Urbana de Robert E. Park. Trad. Wanda Brant. Rio de Janeiro: UFRJ, 2018.

ZAFFARONI, Eugenio Raul. Em busca das penas perdidas: a perda de legitimidade do sistema penal. Rio de Janeiro:Revan, 1991.

ZAFFARONI, Eugenio Raúl; PIERANGELI, José Henrique. Manual de direito penal brasileiro: parte geral.7. ed. rev. e atual. São Paulo: Revista dos Tribunais, 2007. 